\title{
Roadmap Tecnológico para Desenvolvimento de Sistema de Monitoramento da Cura do Concreto
}

\author{
Technological Roadmap for Development of Concrete \\ Cure Monitoring System
}

\author{
José Edilson dos Santos Júnior ${ }^{1}$ \\ Vivianni Marques Leite dos Santos ${ }^{1}$ \\ Isnaldo José de Souza Coelho ${ }^{1}$ \\ ${ }^{1}$ Universidade Federal do Vale do São Francisco, Petrolina, PE, Brasil
}

\begin{abstract}
Resumo
A construção civil é importante para o desenvolvimento social e econômico dos países. Nesse setor, destaca-se o concreto armado, conferindo resistência aos esforços de compressão e de proteção ao aço. Durante execução de obras, há necessidade de aguardar tempo para endurecimento do concreto (tempo de pega), cuja decisão inadequada acerca da finalização pode gerar custos ou até mesmo acidentes graves. O objetivo desse artigo é elaborar roadmap tecnológico a partir de estudo prospectivo e identificação de elementos internos e externos que influenciam o desenvolvimento de sistema para monitoramento da pega do concreto. Assim, fez-se necessária a busca e a análise de patentes, seguida de análise SWOT, e, finalmente, elaboração de roadmap tecnológico contendo produtos, mercado interessado, mercado concorrente e tecnologias necessárias. Conclui-se pela viabilidade do sistema de monitoramento, com benefícios a curto prazo para a academia e expectativa de interesse nos diferentes setores da construção civil, como construtoras, concreteiras e fábricas de pré-moldados.
\end{abstract}

Palavras-chave: Engenharia civil. Concreto armado. Predição.

\begin{abstract}
The construction industry is important in the social and economic development of countries. In this sector, the reinforced concrete is highlighted, providing resistance to compressive forces and protection to steel. During construction processes, there is a need to wait for the concrete to harden (setting time), whose improper decision about finishing can generate costs or even serious accidents. The objective of this paper is to elaborate a technological roadmap based on a prospective study and identification of internal and external elements that influence the development of a concrete cure monitoring system. For this, it was necessary to search and analyze patents, followed by SWOT analysis and, finally, elaboration of technological roadmap containing products, interested market, competing market and necessary technologies. It concludes by the viability of the monitoring system, with short-term benefits for the academy and expectation of interest in different sectors of construction, such as construction companies, concrete and precast factories.
\end{abstract}

Keywords: Civil engineering. Reinforced concrete. Prediction.

Área Tecnológica: Inovação. Prospecção Tecnológica e Desenvolvimento. 


\section{Introdução}

O concreto é o mais importante material usado na construção civil e, devido às suas inúmeras vantagens, tem sido o material mais usado na construção de residências, prédios, indústrias, pontes, viadutos, barragens, túneis, silos, reservatórios, etc. Entre as vantagens do uso desse material destacam-se o baixo custo, a facilidade de aquisição dos materiais componentes, a versatilidade, a adaptabilidade, a durabilidade e a possibilidade de incorporar com rejeitos industriais poluentes (GALVÃO, 2003).

Quanto à composição, o concreto é preparado por meio da mistura de cimento, agregados miúdos e graúdos, e água, que quando misturados oferecem uma condição de plasticidade. Tal condição assegura a facilidade de transporte, lançamento, adensamento. Sua resistência e durabilidade dependem da proporção entre os materiais que o constituem. Adicionalmente, a mistura entre os materiais constituintes é chamada de dosagem ou traço (HELENE; ANDRADE, 2010).

Ainda sobre a mistura para a composição do concreto, o cimento é o elemento fundamental de ligação (cola) entre os agregados, essa cola é o elemento mais fraco da composição e, portanto, determina a resistência final do concreto.

Em uma estrutura de concreto armado, o material concreto possui duas funções básicas, a primeira relativa à resistência dos esforços de compressão, cuja estrutura estará submetida, e a segunda com a função de conferir proteção ao aço.

O papel da água utilizada para composição do concreto está na sua contribuição para a reação química que transforma o cimento em uma pasta aglomerante. Quando a água é adicionada em pequena quantidade, a reação não ocorrerá por completo e também a facilidade de se adaptar às fôrmas ficará prejudicada, porém se a quantidade for superior à ideal, a resistência diminuirá em função dos poros que ocorrerão quando esse excesso evaporar. A porosidade, por sua vez, tem influência na impermeabilidade e, consequentemente, na durabilidade das estruturas confeccionadas em concreto. A proporção entre a água e o cimento utilizados na mistura é chamada de fator água/cimento e as proporções entre areia e brita na mistura tem influência na facilidade de se adaptar às fôrmas e na sua resistência (HELENE; ANDRADE, 2010; SILVA, 2006).

Devido às propriedades físico-químicas do concreto variarem de acordo com seu estado físico (fresco ou endurecido), o concreto deve ser analisado nessas duas condições: fresco $e$ endurecido. O concreto fresco é assim considerado até o momento em que tem início a pega do aglomerante e o concreto endurecido é o material que se obtém pela mistura dos componentes, após o fim da pega do aglomerante (TUTIKIAN; HELENE, 2011).

Para o concreto fresco, as propriedades desejáveis são as que asseguram a obtenção de uma mistura fácil de transportar, lançar e adensar, sem segregação. As principais propriedades do concreto, quando fresco, são: consistência, plasticidade, poder de retenção de água, trabalhabilidade, enquanto que s características que um concreto depois de endurecido deve possuir são: resistência, durabilidade, impermeabilidade e aparência. Todas essas características, à exceção da aparência, melhoram sensivelmente com o uso adequado da relação água/cimento (TUTIKIAN; HELENE, 2011). 
Bauer (2000) conclui acerca da correlação entre as propriedades do concreto fresco e aquelas dos concretos endurecidos, bem como suas influências na qualidade final dos elementos de concreto em uma obra, tais como tempo de início e fim de pega, calor de hidratação, densidade, resistência à abrasão, condutibilidade elétrica, propriedades térmicas, propriedades acústicas, etc.

Por outro lado, na prática, os responsáveis pelo acompanhamento e execução das obras se deparam com o gargalo de tempo que está associado ao endurecimento do concreto ou tempo de pega durante execução das obras, cuja decisão inadequada acerca da desmoldagem pode gerar custos desnecessários e até mesmo perigo de acidente. $\mathrm{O}$ auxílio de sensores e sistemas para monitoramento de propriedades físico-químicas correlacionadas a cura do concreto pode proporcionar a obtenção de respostas mais eficientes que possibilitem diminuir os tempos de desmoldagem das fôrmas ou peças, com ganhos financeiros, de tempo e segurança para as construtoras. Por outro lado, a execução de projetos de desenvolvimento tecnológico dessa natureza gera ganhos intangíveis relacionados a propriedade intelectual com adequada proteção, além de formação de recursos humanos para o desenvolvimento tecnológico no setor da construção civil.

Nesse contexto, a possibilidade de correlação entre o início e fim de pega do concreto com as demais propriedades descritas por Bauer (2000) constituiu motivação para analisar as forças, fraquezas, ameaças e oportunidades, elementos constitutivos de uma matriz SWOT (AKTOUF, 2002), com vistas à expectativa de viabilidade para execução de projeto, dado que a referida matriz permite explicitar influências interna e externa para execução da pesquisa e desenvolvimento tecnológico, tais como a aplicação de sensores para obtenção da celeridade e segurança requeridas em obras de construção civil, proposta desse estudo.

Os elementos externos (ameaças e oportunidades) são adicionados à matriz, à medida que são identificadas, por meio do estudo prospectivo, tecnologias desenvolvidas por pesquisadores, as quais estão em domínio público (artigos disponíveis na literatura) e também aquelas tecnologias a partir de empresas/empreendedores, protegidas por meio de patentes. Por outro lado, os elementos internos (forças e fraquezas) são analisadas a partir da identificação dos recursos disponíveis para desenvolvimento do projeto, como infraestrutura, equipe, etc. Finalmente, com base no estudo prospectivo e identificação dos elementos internos e externos, o roadmap tecnológico contribui para maior eficiência e eficácia no desenvolvimento de projeto, com previsão a curto, médio e longo prazo.

Nesse ínterim, destaca-se que a matriz SWOT auxilia sobremaneira os diversos processos de tomada de decisão, tendo ampla gama de aplicações. Paim e Almeida (2018), por exemplo, no seu estudo prospectivo sobre a utilização de impressora 3D na construção civil, destacaram que a elaboração da matriz permitiu identificar e avaliar peculiaridades do setor, auxiliando no conhecimento interno e externo das empresas e proporcionando análises necessárias para busca pela melhoria contínua.

Isso posto, com o propósito de desenvolver tecnologia para monitoramento e predição das propriedades do concreto, este artigo tem como objetivo o estudo prospectivo, elaboração de matriz SWOT e finalmente, culminar com o Roadmap Tecnológico a ser utilizado durante o desenvolvimento do projeto, para tomadas de decisão, dado que contém o plano de ação, com previsão das atividades a curto, médio e longo prazo, com visualização das tecnologias, produtos e mercados inter-relacionados. 


\section{Metodologia}

Para elaboração do roadmap tecnológico foi realizado estudo preliminar sobre os desenvolvimentos de tecnologias associadas ao monitoramento da cura do concreto (etapa pré-prospectiva - Figura 1), cuja leitura e análise dos artigos com aplicação de tecnologias de monitoramento do concreto permitiu identificação das palavras-chave adequadas para ampla busca de anterioridade e análise dos dados resultantes da prospecção tecnológica. Destaca-se que as etapas pré-prospectiva e prospectiva envolveram buscas em periódicos da CAPES e consultas em livros da área, com busca por patentes (Etapa prospectiva - Figura 1).

As informações obtidas à partir do estudo prospectivo adicionadas aos aspectos internos e externos que influenciam o desenvolvimento de sistema para monitoramento da cura do concreto por meio de análise SWOT (Strenghts, Weaknesses, Opportunities, Threats) foi confeccionado o Roadmap Tecnológico, conforme metodologia descrita na Figura 1, adaptada de Borschiver e Silva (2016).

Figura 1 - Metodologia para a elaboração do Roadmap tecnológico

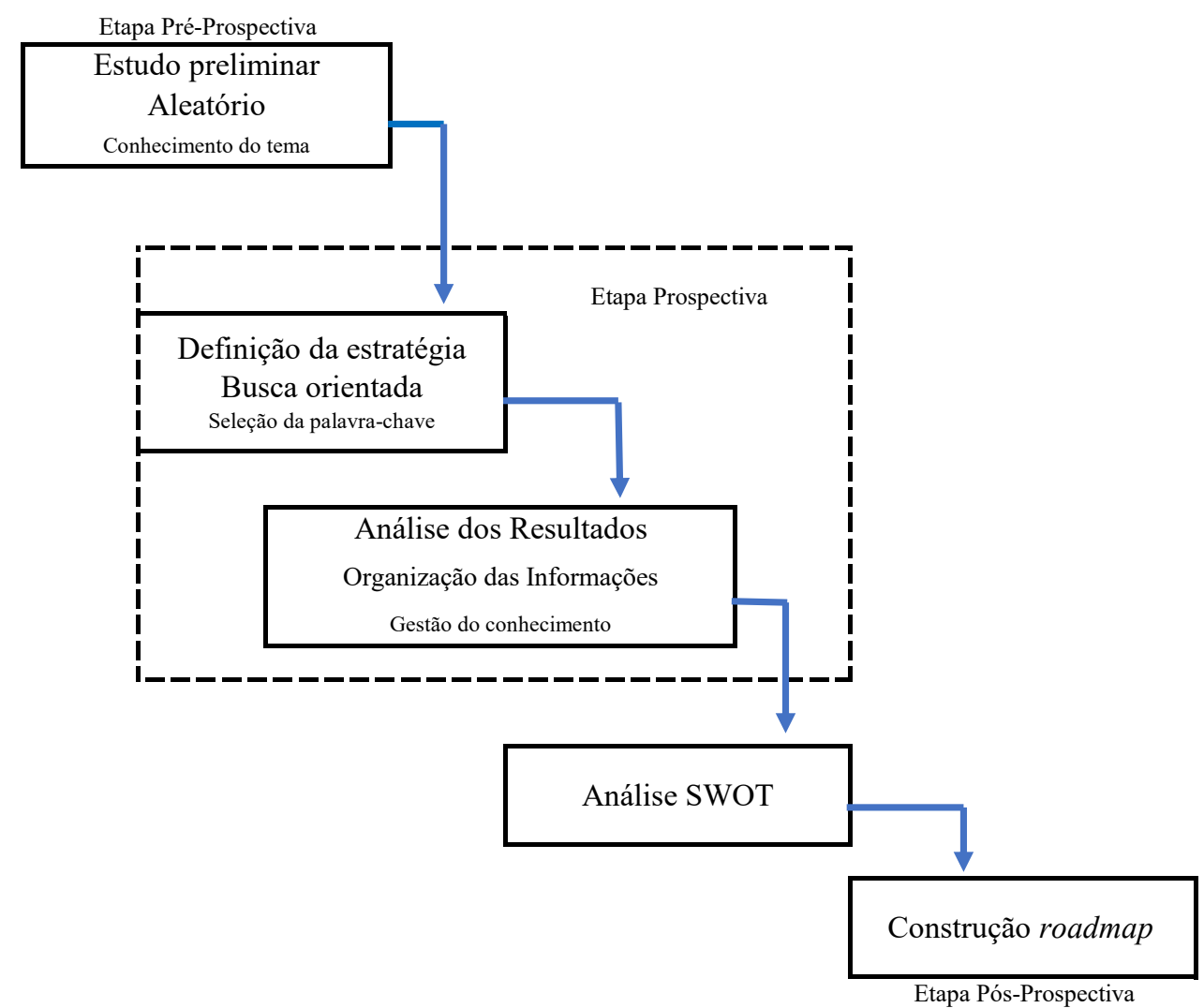

Fonte: Adaptada de Borschiver e Silva (2016)

Na etapa Pré-prospectiva, foi feita uma busca aleatória sobre o concreto, sua importância e propriedades, para, assim, se ter uma visão geral do assunto referente ao projeto a ser desenvolvido e, consequentemente, auxiliar nas escolhas das palavras-chave que combinadas deram subsídios à etapa prospectiva do processo.

Com o escopo do projeto definido e com as palavras-chave escolhidas, seguiu-se para a segunda etapa, a fase prospectiva, na qual foi realizada a busca sem restrição, ou seja, em todos os escritórios contemplados pelo software (CQuestel Orbit (2018), combinando as palavras-chave 
"Properties of concrete", "concrete cure" e "Concrete cure monitoring". Esta pesquisa foi efetuada para um período compreendendo os últimos 10 anos (1998 a 2018).

Segundo Borschiver e Silva (2016), a maturidade das informações geradas a partir das buscas efetuadas podem ser divididas em quatro fases de tempo: estágio atual, curto prazo, médio prazo e longo Prazo.

$\mathrm{Na}$ fase de estágio atual foram encontradas informações do estado atual de uso e a necessidade efetiva da tecnologia que será desenvolvida neste projeto. Essas informações foram obtidas por meio da mídia especializada, sites das empresas do setor etc., que nos permitiu um aprofundamento da real necessidade da tecnologia a ser desenvolvida.

Na fase de Curto Prazo foram analisadas as patentes concedidas (granted) para sistemas de monitoramento da cura do concreto, que, em tese, já contém um grau avançado de desenvolvimento tecnológico e, consequentemente, a tecnologia está mais próxima de sua fase comercial.

$\mathrm{Na}$ fase de Médio Prazo foram analisadas as patentes solicitadas e/ou pendentes (pendent) que, apesar de demonstrarem um grau avançado do desenvolvimento da tecnologia pelo detentor da patente, como a proteção ainda está sob análise, possivelmente, espera-se que o produto ou processo esteja mais distante de sua fase comercial.

Finalmente, a fase de Longo Prazo, na qual foram analisados os artigos científicos e as patentes revogadas ou mortas, que se encontram em um grau satisfatório de desenvolvimento tecnológico, por estarem em fase de estudo ou, ainda, terem caído em domínio público, no caso das patentes.

Com a pesquisa gerada, obtida por meio do software ${ }^{\circledR}$ Questel Orbit (2018), foi feita uma análise a partir dos resultados gerados e obtidos pelo Orbit para se montar uma base de dados que foi utilizada para montagem e estruturação do roadmap.

Diante da quantidade de resultados encontrados na pesquisa, utilizou-se a metodologia de dividir a análise dos documentos em três fases distintas: Macro, Meso e Micro, conforme realizado por Borschiver e Silva (2016).

$\mathrm{Na}$ etapa macro da análise foram observadas informações superficiais dos resultados, como, título, autor, etc. A partir dessas informações obtidas na etapa macro, passou-se para uma análise mais aprofundada dos documentos elencados na etapa. Então, passa-se para a etapa meso, durante a qual é dado aprofundamento na análise das informações contidas nos documentos examinados na etapa anterior. Nessa etapa, a análise se dá com a leitura dos resumos dos quais foram extraídas as informações principais que servirão de subsídios para a próxima etapa da análise.

Conhecendo os conteúdos dos resumos dos documentos pesquisados, passa-se para uma análise mais detalhada, a etapa micro, onde é efetuada a leitura detalhada de todo o documento para a compreensão e caracterização da tecnologia proposta.

Passadas as etapas Pré-prospectiva e Prospectiva, segue-se para análise dos ambientes internos quanto às fraquezas e às forças do ambiente externo, às oportunidades e às ameaças, ou seja, realiza-se a análise da Matriz SWOT. Na última etapa, a Pós-prospectiva, as informações foram analisadas em forma similar a um "mapa", cujas informações podem ser visualmente destacadas a partir de seus aspectos mais relevantes para o projeto, bem como destacadas suas inter-relações entre o projeto e suas distintas fases, além de permitir sua constante atualização ao longo do processo. 
Assim, no roadmap (Quadro 1) elaborado, foram correlacionados os produtos obtidos, as tecnologias utilizadas para obtenção desses produtos, os possíveis mercados recebedores desses produtos e os mercados com tecnologias concorrentes, tudo isso também levando em consideração o horizonte temporal de curto, médio e longo prazo.

\section{Resultados e Discussão}

A partir da pesquisa orientada, combinando as palavras-chave "Properties of concrete", "concrete cure", "Concrete cure monitoring, foi realizada a busca, no título ou no resumo das famílias de patentes, por meio do software (CQuestel Orbit (2018), sendo identificadas 147 famílias de patentes. A seguir, foram feitas as análises e a discussão em caráter macro, meso e micro, conforme descrito na metodologia.

A partir das análises mais amplas, níveis Macro e Meso (Gráfico 1), das 147 famílias de patentes que abordam as propriedades do concreto, o monitoramento e/ou a cura do concreto, tem-se que a quantidade de famílias de patentes concedidas ou pendentes de análise equivale a 40,88\% do total (60 famílias de patentes), enquanto o número de famílias de patentes mortas, expiradas ou revogadas, corresponde a $59,12 \%$ do total (87 famílias de patentes). Para melhor compreensão, os resultados da análise são discutidos com o auxílio das informações contidas nos Gráficos 2 a 5, a seguir.

Outra informação importante a se destacar é que no intervalo de tempo de 10 anos, apenas $26,5 \%$ das famílias de patentes foram concedidas, o que reporta a problemática do significativo backlog no processo de análise das patentes, cuja discussão não será aprofundada por não constituir foco deste estudo.

Gráfico 1 - Situação Legal das Patentes - Análise Macro e Meso (147 Resultados)

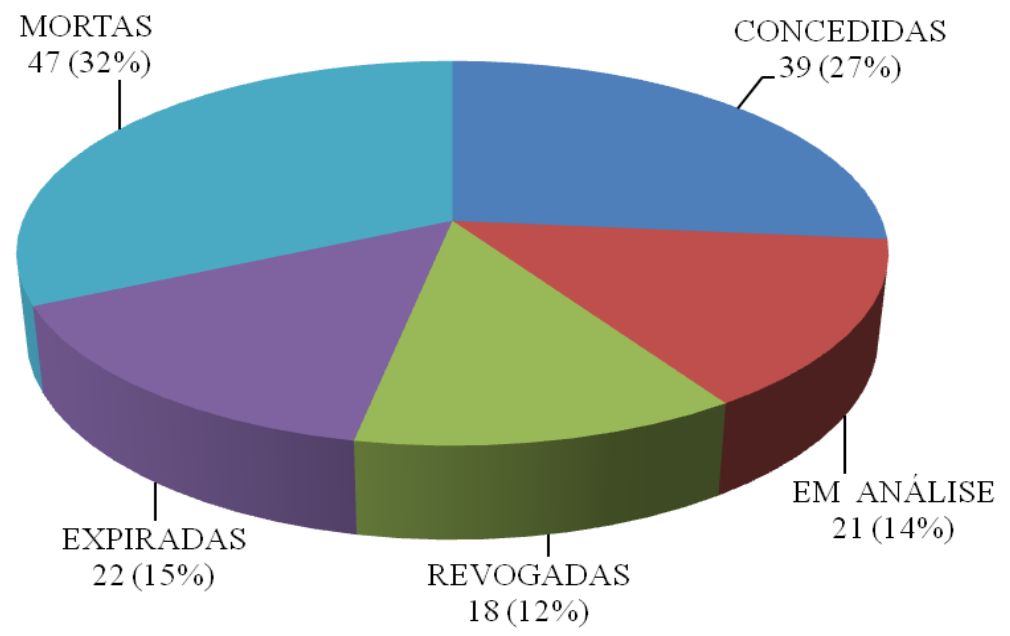

Fonte: Elaborado pelos autores deste artigo a partir dos dados obtidos pelo software (CQuestel Orbit (2018)

Em quantidades de famílias de patentes por país (Gráfico 2) quem se destaca, quantitativamente, nesse tema é o Japão (JP), com 80 famílias de patentes (54,42\% do total), seguido pela China $(\mathrm{CN})$ com menos da metade da produção identificada no Japão, com 24 famílias de patentes (16,32\%). A seguir, registra-se a República da Coreia e os Estados Unidos, com 
13 famílias de patentes cada, representando apenas 8,84\% para cada. Apesar dos números expressivos para um dado país, a análise mais detalhada, na fase micro, permite conclusões mais assertivas quanto àquelas famílias de patentes já concedidas.

Gráfico 2 - Quantidade de famílias de patentes por país. Análise Macro e Meso (147 Resultados)

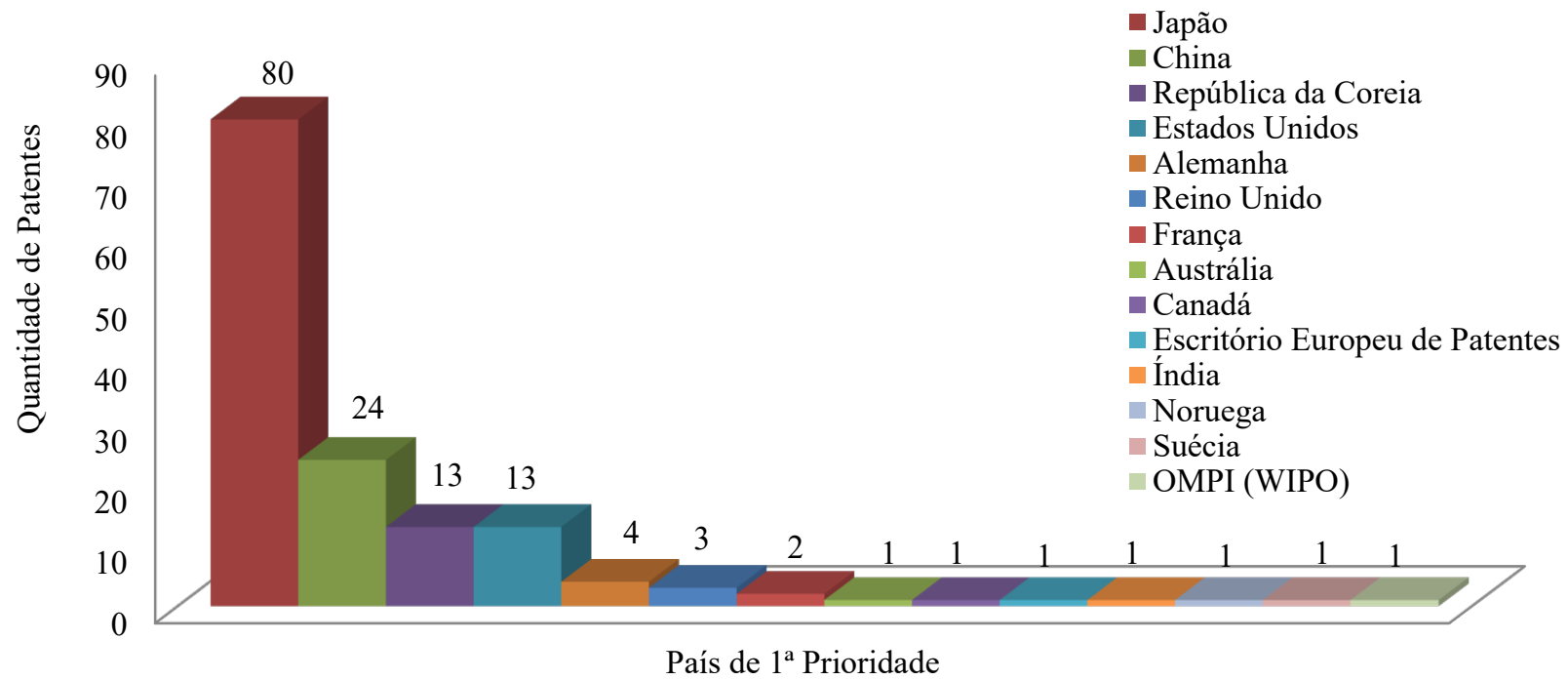

Fonte: Elaborado pelos autores deste artigo a partir dos dados obtidos do software (cQuestel Orbit (2018)

Dessa forma, pode-se concluir que, de 1998 a 2018, o Japão (JP) e a China (CN) dominaram as tecnologias na área de propriedades do concreto, monitoramento ou desenvolvimentos para cura do concreto. A leitura do resumo das patentes também permitiu concluir que os estudos acerca da cura do concreto correspondem a 70,75\% do total das famílias de patentes publicadas, com maior destaque para o Japão.

Com base na análise do Gráfico 3, entre os anos de 1998 e 2018, verifica-se que as publicações de famílias de patentes acerca da cura do concreto vêm ocorrendo com comportamento não linear ao longo dos anos, ou seja, com comportamentos crescente e decrescente em diferentes períodos.

Gráfico 3 - Quantidade de famílias de patentes por ano de $1^{\text {a }}$ prioridade - Análise Macro e Meso

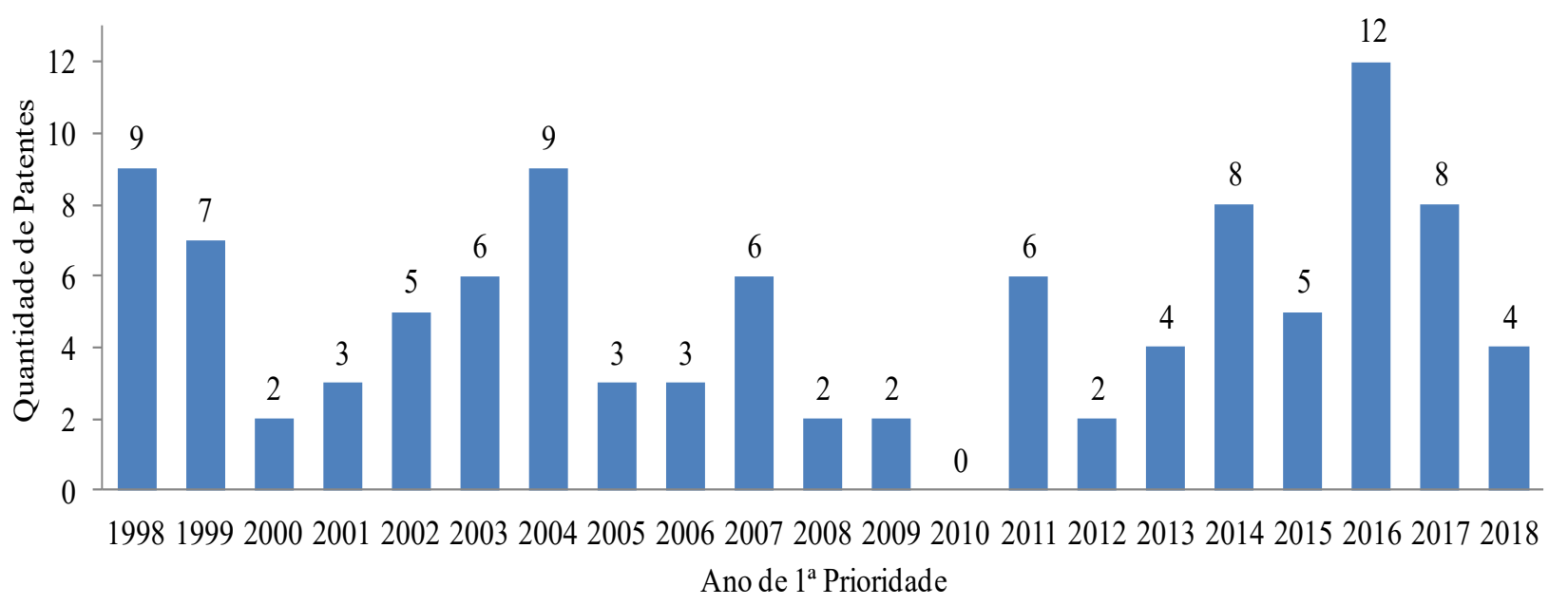

Fonte: Elaborado pelos autores deste artigo a partir dos dados obtidos pelo software (CQuestel Orbit (2018) 
A produção mais expressiva ocorreu no ano de 2016, com 12 famílias de patentes. No período dos 10 anos, destaca-se metade (cinco anos) com números significativos, quando comparados aos demais (igual ou acima de oito patentes) nos anos de 1998, 2004, 2014, 2016 e 2017. Ao passo que apenas no ano de 2010 não houve depósito de patente na área, em qualquer país do mundo.

No Gráfico 4, percebe-se que as empresas Japonesas Tokai Rubber Industries e Seiku Chemical dominam o mercado dependente de invenções protegidas por patentes relacionadas ao concreto com 22 patentes, enquanto em menor evidência, mas entre as "top 10" vem Det Norsk Veritas, East Japan Railway, Hidepyon e Huangshi Huibo, com apenas duas patentes cada.

Gráfico 4 - Quantidade de Patentes por Empresa Detentoras - Análise Macro e Meso (147 Resultados)

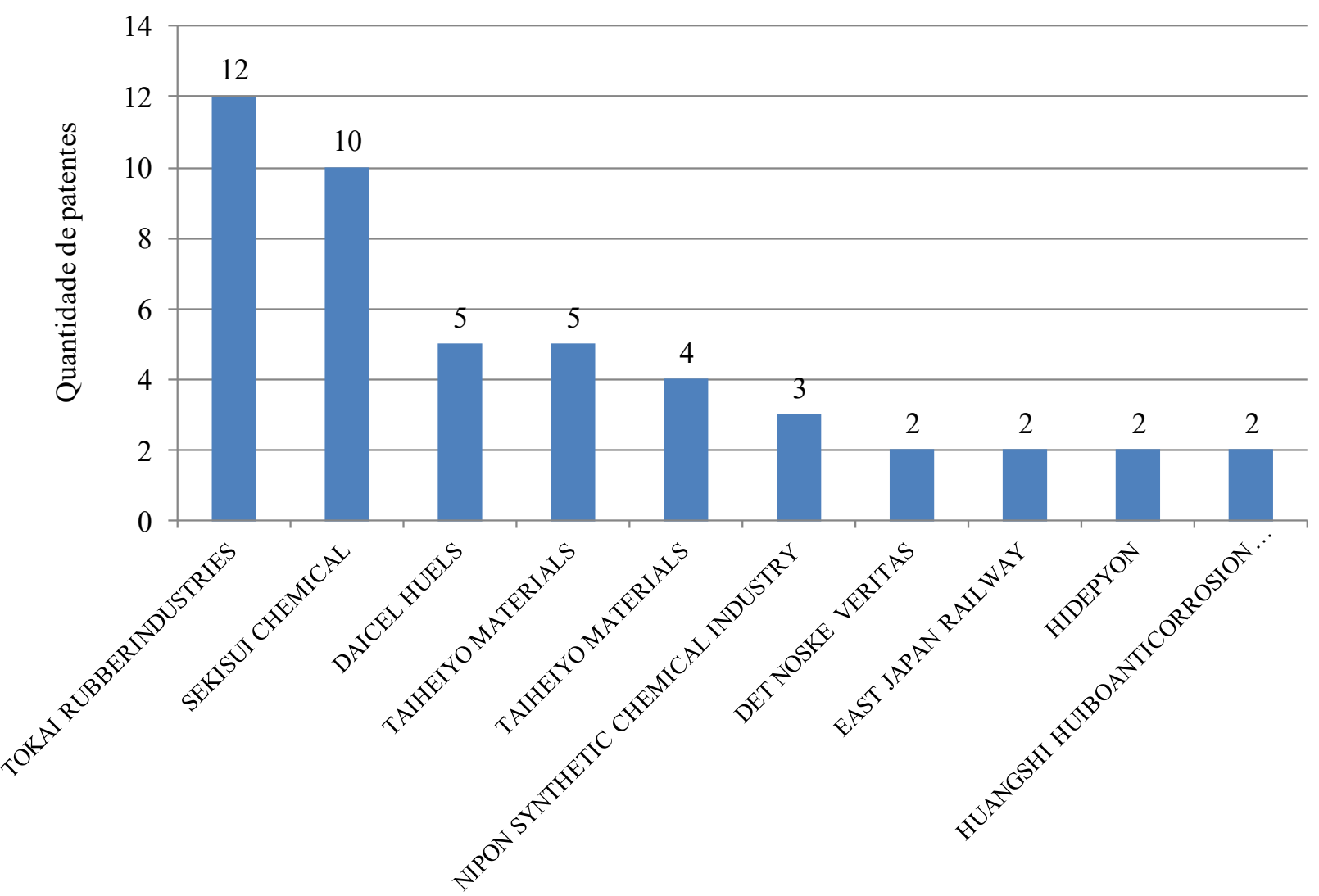

Fonte: Elaborado pelos autores deste artigo a partir de dados fornecidos pelo software (CQuestel Orbit (2018)

Adicionalmente, verifica-se que os estudos relativos à cura do concreto têm suas áreas de atuação mais fortes no setor da construção civil (Figura 2), porém, devido a sua multidisciplinaridade, também encontra patentes nas áreas de materiais de metalurgia e outras máquinas especiais. 
Figura 2 - Visão geral do campo tecnológico - Análise Macro e Meso (147 Resultados)

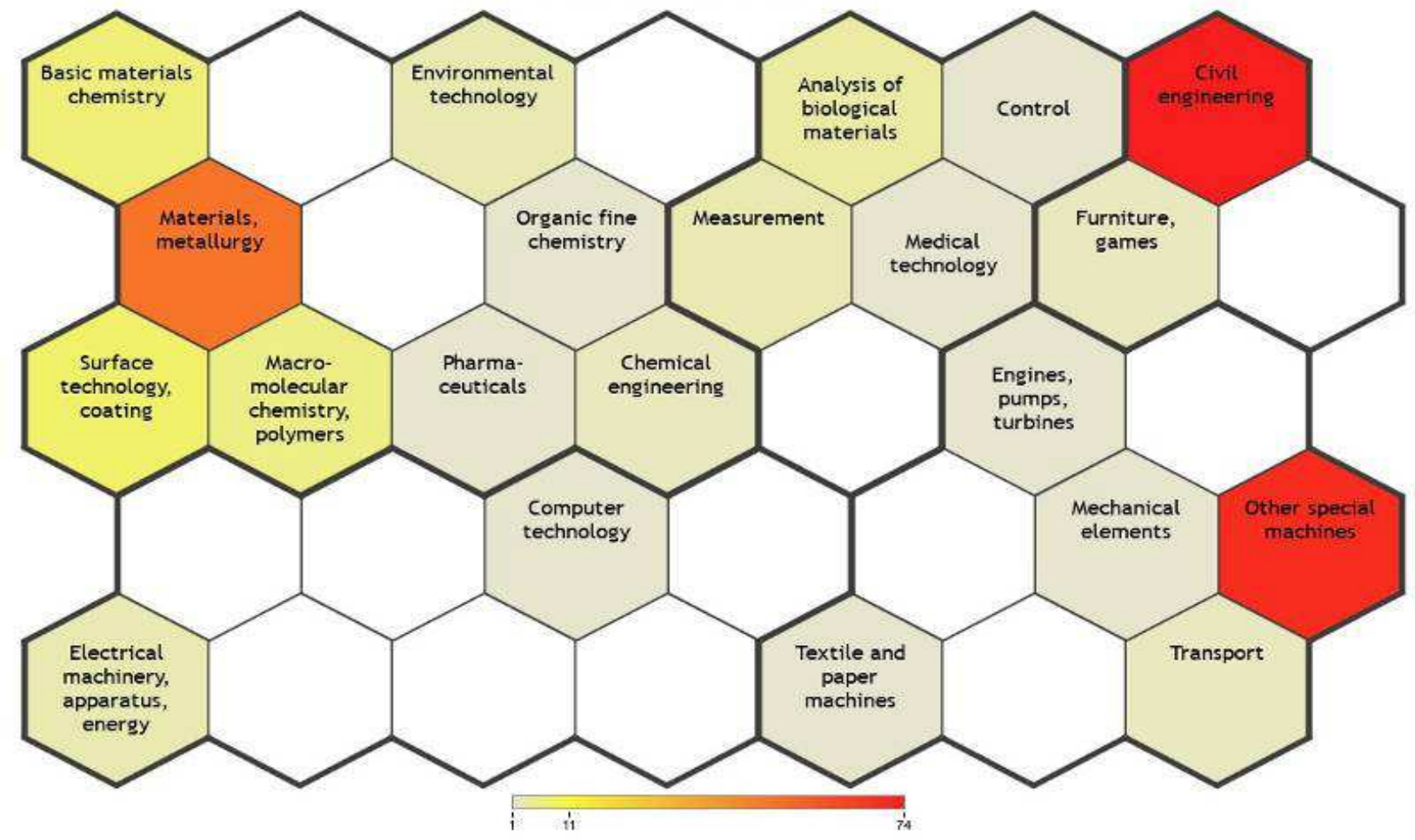

Fonte: Software (CQuestel Orbit (2018)

Em uma análise em nível Micro (Gráficos 5 a 7), verifica-se que a grande maioria das famílias de patentes aborda desenvolvimento de tecnologias para a cura do concreto, mas não em nível de monitoramento por meio de sensores, sendo elencadas apenas sete famílias de patentes que abordam sistemas de monitoramento aplicado à cura do concreto, de modo que apenas essas famílias de patentes foram consideradas para elaboração do roadmap tecnológico para desenvolvimento de sensores para monitoramento da cura do concreto (Figura 4).

Gráfico 5 - Situação legal das patentes - Análise Micro (7 Resultados)

$$
\text { -CONCEDIDAS } \backsim \text { PENDENTES } \square \text { REVOGADAS } \backsim \text { MORTAS }
$$

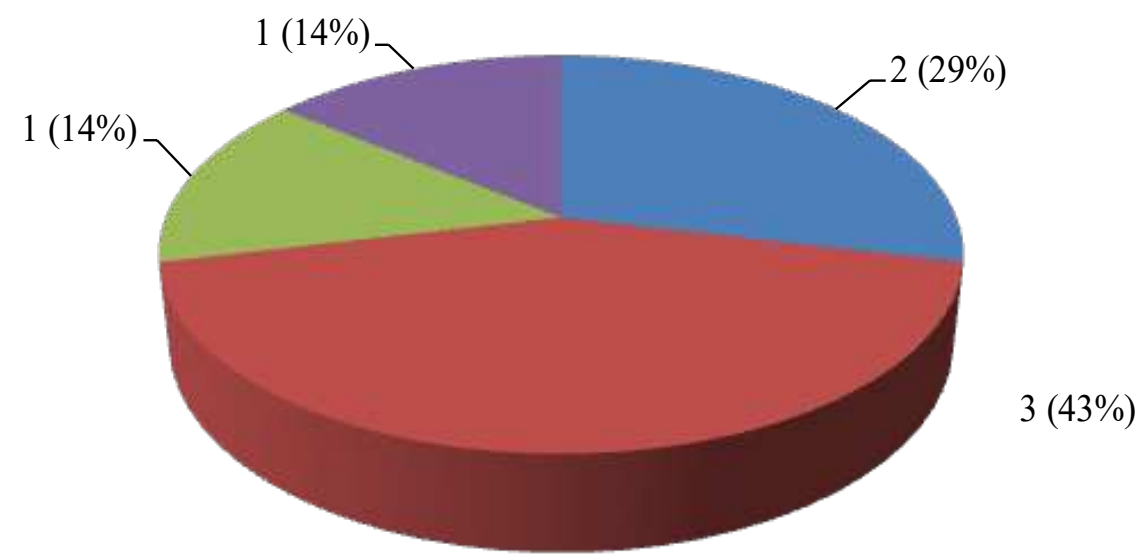

Fonte: Elaborado pelos autores deste artigo a partir pelo software (CQuestel Orbit (2018) 
Gráfico 6 - Empresas por situação legal das patentes - Análise Micro (7 Resultados)

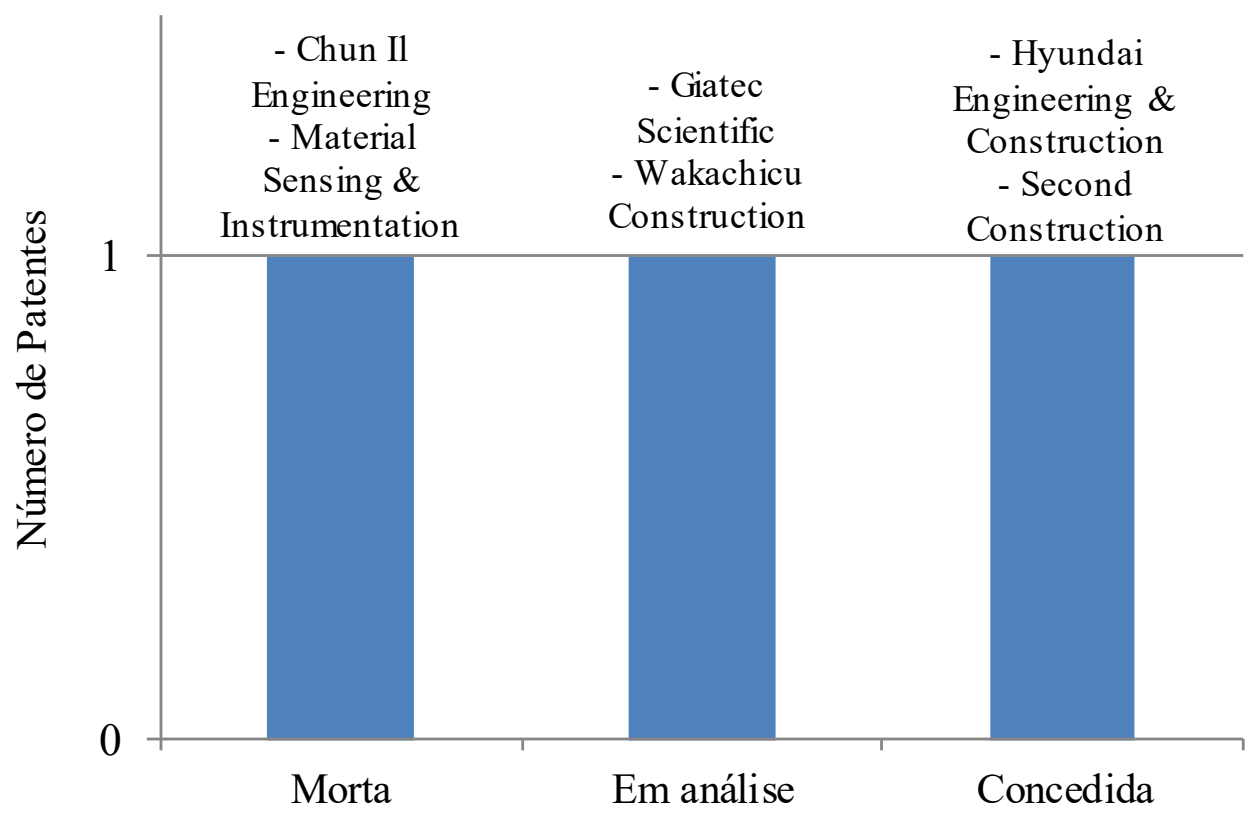

Fonte: Elaborado pelos autores deste artigo a partir do software @QQuestel Orbit (2018)

Das sete famílias de patentes elencadas nesta etapa, duas registram concessão em alguns dos países em que foram depositadas, três estão pendentes de concessão e apenas duas famílias de patentes estão mortas ou revogadas. Então, tem-se 71,43\% de material tecnológico teoricamente pronto para o mercado (cinco famílias de patentes). As informações contidas nessas patentes serão consideradas durante o desenvolvimento do projeto em tela, visando à necessidade de elementos inovativos que caracterizem significativa distinção. As outras duas famílias de patentes (28,57\%), apesar de estarem em domínio público e não passíveis de proteção, também possuem informações importantes que precisam ser analisadas no desenvolvimento e na diferenciação do produto requerido nesse projeto.

As empresas Hyundai Engineering e Second construction (Gráfico 6), por já terem patentes concedidas, têm condições de transferir essa tecnologia a um curto prazo, enquanto a Giatech Scientific e a Wakachicu construction, devido as suas famílias de patentes ainda estarem aguardando análise, preveem suas tecnologias no mercado em um médio prazo. Já as tecnologias desenvolvidas pelas empresas Chun Il Engineering e Material Sensing \& Instrumentation, por suas patentes não terem sido concedidas, mas estarem em domínio público, preveem que poderão compor o mercado mesmo que a longo prazo.

Conforme pode ser visualizado na Figura 3, as famílias de patentes identificadas para essa análise Micro estão protegidas apenas em alguns Países da América do Norte e da Ásia. Destaca-se, ainda, que os países que dominam e detêm a tecnologia de monitoramento da cura do concreto são os Estados Unidos, o Canadá, o Japão, a China, a Índia e a República da Coreia. 
Figura 3 - Família de patentes por País de Proteção. Análise Micro (7 Resultados)
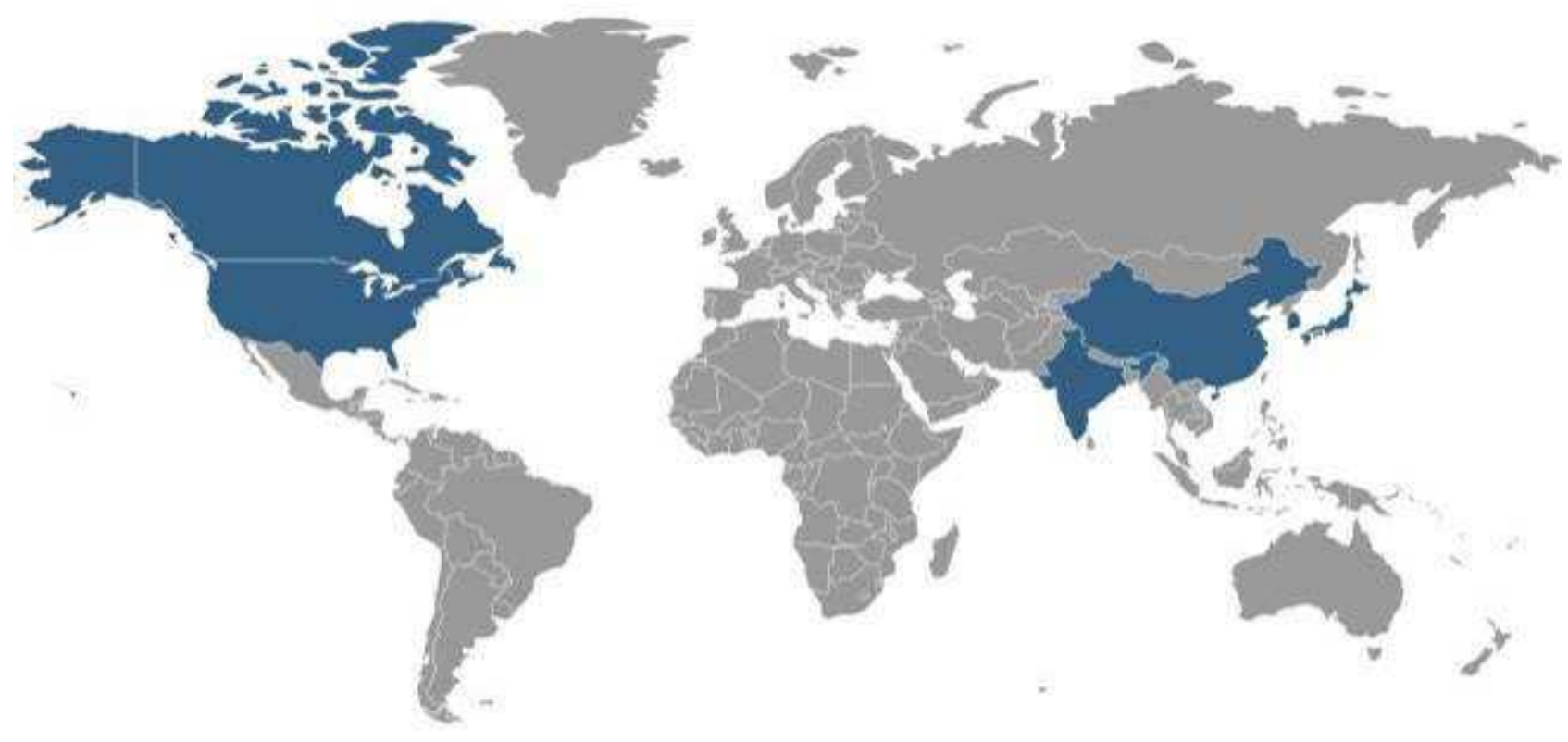

1

Fonte: Software (OQuestel Orbit (2018)

Sendo a matriz SWOT (Quadro 1) destacada por Ferreira et al. (2018) como uma facilitadora para identificação do posicionamento de uma tecnologia no mercado, sua elaboração permitiu identificar informações importantes para caracterização dos ambientes internos (forças e fraquezas) e externos (oportunidades e ameaças) para o desenvolvimento do projeto proposto. Sua análise permitiu avaliar os aspectos tantos positivos quanto negativos referentes aos ambientes internos e externos do projeto e, a partir daí, escolher a melhor estratégia para planejamento e execução das etapas de realização do projeto que estão detalhadas no roadmap (Figura 4) analisado a seguir.

No ambiente interno, foram avaliadas as forças e fraquezas do projeto de sistema de monitoramento para a cura do concreto, tendo como principais forças para execução do projeto a disponibilidade de equipe qualificada para execução, composta de profissionais e estudantes de várias áreas do conhecimento com participação prevista no processo. Também é considerada uma grande força para o projeto o fato dele ser desenvolvido em uma universidade federal, bem estruturada e comprometida com o tema da inovação. Nela, pode-se fazer parcerias com os diversos grupos de pesquisa e nas diversas áreas da engenharia, utilizando seus laboratórios para desenvolver e conseguir os melhores resultados para obtenção do sistema proposto.

Já entre as fraquezas, foi identificada a ausência de recursos para remuneração da equipe envolvida, visto que o país passa por uma situação político-econômica instável, diminuindo, assim, a possibilidade de se conseguir editais de apoio junto aos órgãos de fomento. Outra fraqueza encontrada foi a pouca familiaridade da equipe em trabalhar com pesquisa aplicada $e$ também pouco conhecimento com os temas referentes à inovação tecnológica, à propriedade intelectual e à transferência de tecnologia, isso verificado entre os participantes discentes da graduação. 
Quadro 1 - Matriz SWOT para um projeto de desenvolvimento de Sistema para Monitoramento da Cura do Concreto

\begin{tabular}{|c|c|}
\hline \multicolumn{2}{|c|}{ MATRIZ SWOT } \\
\hline Forças & Fraquezas \\
\hline $\begin{array}{c}\text { - Equipe qualificada } \\
\text { - Disponibilidade de softwares } \\
\text { de pesquisa avançados } \\
\text { - Equipe multidisciplinar } \\
\text { - Parcerias com grupos de pesquisa com } \\
\text { competências/recursos complementares }\end{array}$ & $\begin{array}{c}\text { - Ausência de recursos para remuneração da equipe } \\
\text { - Pouca familiaridade da equipe de } \\
\text { trabalho com pesquisa aplicada } \\
\text { - Falta de capacitação para inovação da equipe }\end{array}$ \\
\hline Oportunidades & Ameaças \\
\hline $\begin{array}{c}\text { - Reaquecimento do mercado } \\
\text { para construção civil } \\
\text { - Tendência à automatização do processo } \\
\text { de monitoramento remoto (indústria 4.0) } \\
\text { - Perfil da política de pesquisa e } \\
\text { desenvolvimento do governo que se } \\
\text { inicia para inovação nas IFES } \\
\text { - Expansão das tecnologias de } \\
\text { monitoramento na construção civil }\end{array}$ & $\begin{array}{l}\text { - Pouco apoio das instituições para a inovação } \\
\text { - Tecnologias concorrentes } \\
\text { - Situação político-econômica atual } \\
\text { - Critérios de avaliação dos editais para inovação }\end{array}$ \\
\hline
\end{tabular}

Fonte: Elaborado pelos autores deste artigo

No ambiente externo, sugere-se, como oportunidade, o reaquecimento, mesmo que lento, do mercado da construção civil, que, a partir da indústria 4.0, aponta para uma tendência de automação dos processos de monitoramento remoto. Outra oportunidade importante a ser destacada está no recente perfil da política de pesquisa do governo, que propõe ações para inovação com apoio das Instituições Federais de Ensino Superior (IFES).

Por outro lado, a baixa produção a partir das IFES para desenvolvimento tecnológico e inovação vem ameaçando o avanço em diversas áreas do conhecimento, devido à falta de cultura relacionada à pesquisa aplicada, à inovação $e$ às dificuldades políticas e econômicas que o Brasil vem passando. Além disso, os autores deste artigo sugerem a revisão dos critérios de avaliação dos editais de fomento e de avaliação de pesquisadores, no sentido de incentivar a pesquisa para inovação.

O estudo prospectivo permitiu definir como ameaças externas, as tecnologias já desenvolvidas, sendo incluídas no roadmap tecnológico (Figura 4) na análise de mercado concorrente, embora, também, verificando-se que as empresas com tecnologias concedidas não protegeram no Brasil e que há muito avanço a ser desenvolvido, o que caracteriza novas oportunidades que permitem identificar a viabilidade para o desenvolvimento proposto netse estudo, além de vislumbrar aplicações a partir da identificação de problemas atuais e possíveis soluções. 
Figura 4 - Roadmap Tecnológico - Sistema de monitoramento da cura do concreto

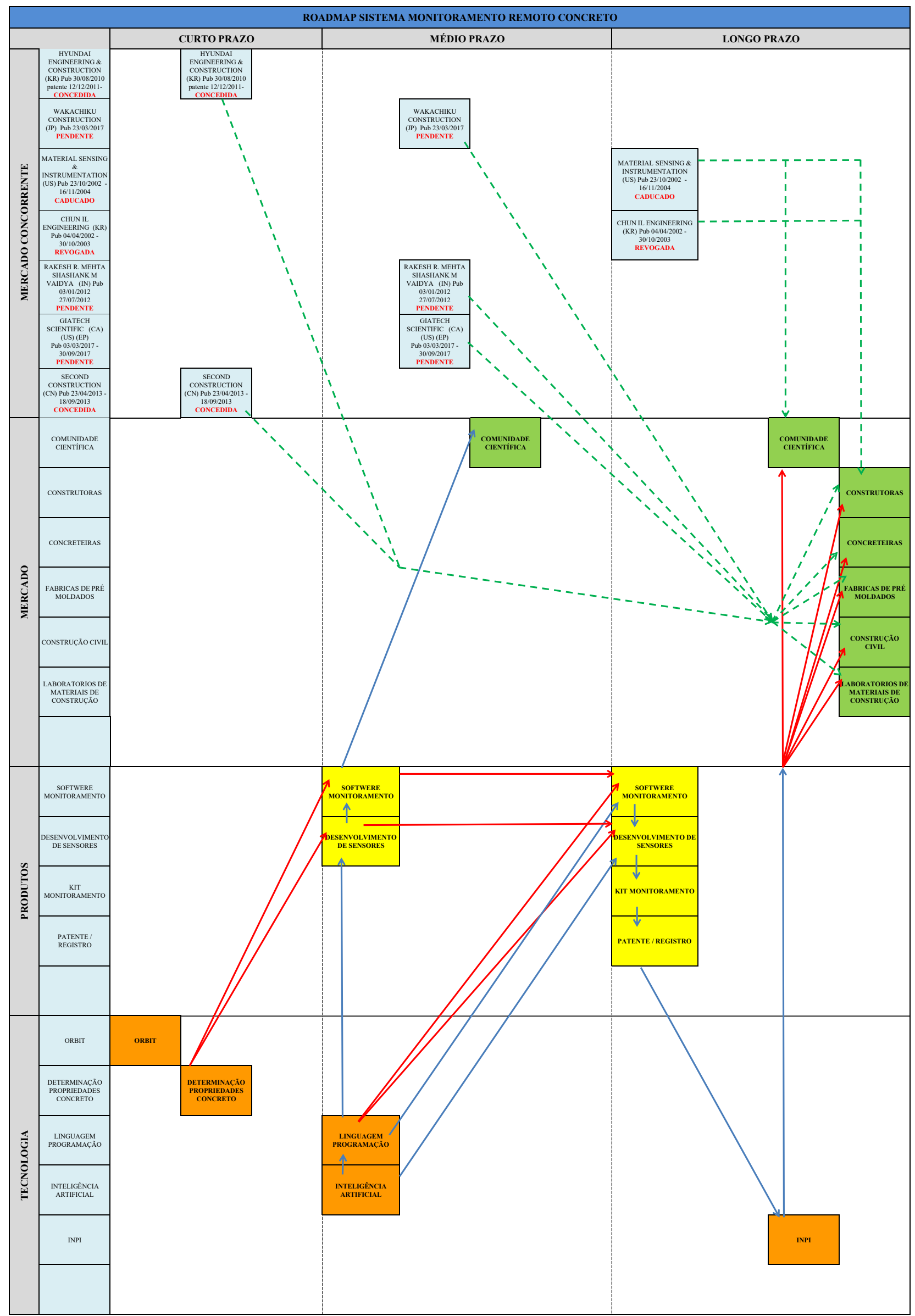

Fonte: Elaborado pelos autores deste artigo 
De acordo com as especificidades demandadas para o desenvolvimento do projeto, o roadmap tecnológico (Figura 4) contém quatro objetos de análise a curto, médio e longo prazo, que são as tecnologias necessárias para execução da pesquisa e montagem do protótipo (linha 4 - Figura 4); os produtos obtidos ao longo do desenvolvimento da pesquisa (linha 3 - Figura 4); o mercado interessado na tecnologia (linha 2) e as possíveis tecnologias concorrentes (linha 1 - Figura 4).

A curto prazo, conforme descrito no roadmap tecnológico (linha 4 - Figura 4), há necessidade de determinação das propriedades físicas do concreto, cuja execução é viável, dado que foi identificada como força, durante análise SWOT (Quadro 1), que há disponibilidade de infraestrutura, equipe multidisciplinar qualificada e interação com grupos de pesquisa com competências e recursos complementares.

Essa força também indica viabilidade, a médio e longo prazos, para escolha e uso de linguagem de programação e inteligência artificial para desenvolvimento de software, previsto como um dos produtos da pesquisa (linha 3 - Figura 4) a médio prazo, o qual deverá conter modelo para correlação entre as propriedades físicas e o tempo de cura do concreto, bem como, a longo prazo, seu aprimoramento até que alcance do produto final, referente ao kit de monitoramento da cura do concreto.

O produto final correspondente ao kit é composto de software e sensores para captação das propriedades do concreto, o qual será devidamente protegido por meio da elaboração $e$ depósito de patente (linha 3 - Quadro 1). Destaca-se que o longo prazo refere-se ao período máximo de dois anos, tempo para finalização do mestrado profissional ao qual está associado o roadmap tecnológico.

Paralelamente, como resultado do estudo prospectivo acerca dos produtos e/ou processos tecnológicos já desenvolvidos, conforme discutido anteriormente sobre sete famílias de patentes (Gráfico 6), destaca-se que duas famílias de patentes estão incluídas no roadmap (linha 1 - Figura 4), por meio de seus titulares, Hyundai Engineering \& Constrution e Second Construction, como possível mercado concorrente a curto prazo, devido seus status de "concedida".

Das cinco patentes restantes, três estão aguardando análise (estado pendente), sendo adicionadas como mercado concorrente a médio prazo e as outras duas, por estarem caducadas ou revogadas, foram incluídas no roadmap tecnológico (linha 1 - Figura 4), como mercado concorrente a longo prazo.

Finalmente, o mercado (linha 2 - Figura 4) que será beneficiado no primeiro momento (médio prazo) será a comunidade científica, e a longo prazo estima o interesse de todo o setor da construção civil, como as construtoras, as concreteiras, as fábricas de pré-moldados e os laboratórios de materiais de construção civil.

Assim, o roadmap tecnológico constitui ferramenta que minimiza a opção por caminhos inadequados, os quais iriam gerar custos, não cumprimento de prazos ou mesmo a inviabilidade do produto planejado. Isso posto, os resultados obtidos nortearão o desenvolvimento tecnológico de produto inovador para monitoramento do concreto durante execução de obras, visando a uma maior agilidade, segurança e rentabilidade nas construções devido ao monitoramento do processo de cura do concreto. 


\section{Considerações Finais}

O setor da construção civil necessita de novas tecnologias para dar mais agilidade, segurança e rentabilidade aos processos construtivos. Atualmente, os responsáveis acompanham a execução das obras, em que um dos principais gargalos está associado ao tempo de espera para endurecimento do concreto, cuja decisão pela finalização pode causar sérias consequências.

Com os sensores e sistema a serem desenvolvidos nesse projeto, estima-se que o monitoramento de propriedades correlacionadas à cura do concreto permitirá obter respostas mais eficientes que possibilitam diminuir os tempos de desmoldagem das fôrmas ou peças, com ganhos financeiros e de tempo para as construtoras, sem prejuízo à segurança das edificações.

Foram identificadas apenas sete famílias de patentes com propostas de sistemas de monitoramento da cura do concreto, as quais não são iguais à proposição deste projeto, mas que a análise documental das referidas patentes motivou a adição de elementos inovativos de modo a garantir o aspecto de novidade ao produto foco deste estudo.

Os estudos para o desenvolvimento do projeto se encontram no campo acadêmico, com o diferencial de constituir demanda de produto de mestrado profissional de interesse do discente, que com base neste estudo prospectivo e análise dos aspectos externos, foi possível concluir que o desenvolvimento da tecnologia para monitoramento da cura do concreto é viável e promissor, beneficiando a comunidade acadêmica a curto prazo e com expectativa de chegar aos diferentes setores da construção civil, como as construtoras, as concreteiras, as fábricas de pré-moldados, entre outros, a longo prazo.

A elaboração do roadmap tecnológico permitiu o levantamento de objetos de análise, cujas interações e demandas não são facilmente identificadas, de modo que constitui ferramenta essencial para minimizar perdas e otimizar o tempo pelo auxílio à tomada de decisão quanto às rotas a serem seguidas. Nesse caso, em particular, tornaram-se evidentes e de fácil visualização os produtos a serem gerados, os recursos necessários, a influência do ambiente externo durante e após o desenvolvimento e o segmento de clientes ou interessados na tecnologia.

Adicionalmente, a elaboração desse estudo e a execução do projeto gera ganhos intangíveis relacionados à propriedade intelectual com adequada proteção, além de formação de recursos humanos para o desenvolvimento tecnológico no setor da construção civil.

Finalmente, sugere-se como desdobramentos deste estudo, a valoração da tecnologia em desenvolvimento e, em outra vertente não menos importante, a identificação e a discussão sobre as causas e as consequências que levaram países como o Japão e a China ao desenvolvimento e à inovação acelerada, como uma forma de obter evidências a serem usadas como referência no Brasil.

\section{Referências}

AKTOUF, Omar. Governança e pensamento estratégico: uma crítica a Michel Porter. RAE - Revista de Administração de Empresa, São Paulo, v. 42, n. 3. p 43-57. 2002. Disponível em: http:// bibliotecadigital.fgv.br/ojs/index.php/rae/article/viewFile/37597/36588. Acesso em: 13 jul. 2018.

BAUER, L. A. F Materiais de construção civil 1. 5. ed. Revisada. Rio de Janeiro: Editora LTC, 2000. 
BORSCHIVER, Suzana; SILVA, Andreza Lemos Rangel da. Technology roadmap - Planejamento Estratégico para alinhar Mercado-Produto-Tecnologia. Rio de Janeiro: Interciência, 2016.

FERREIRA, Camila Lisdalia Dantas et al. Avaliação Tecnológica sobre Dispositivo Eletrônico para Indução de Simetria. Cadernos de Prospecção, Salvador, v. 11, n. 2, 2018. Disponível em: https://rigs.ufba.br/index.php/nit/article/view/23025/AVALIA\%C3\%87\%C3\%83O\%20 TECNOL\%C3\%93GICA\%20SOBRE\%20DISPOSITIVOS\%20ELETR\%C3\%94NICOS\%20PARA\%20 INDU\%C3\%87\%C3\%83O\%20DE\%20SIMETRIA. Acesso em: 28 ago. 2019.

FRANCESCHINI A. S.; PICCOLI, G. L.; NIENOW, I. Disposição aplicada em sistema de controle dos modos de operação de uma usina asfáltica. BR 1020150133820 A2. Data do depósito: 09/06/2015. Data da publicação: 30 de out. de 2017.

GALVÃO, José Carlos Alves. Estudo das propriedades dos concretos confeccionados com cimento CP v - ARI e CP 11 - F321, sob diferentes temperaturas de mistura e métodos de cura. 2003. 95 p. Dissertação (Mestrado) - Universidade Federal do Paraná, Curitiba, Curitiba, PR, 2003.

HELENE, Paulo; ANDRADE, Tibério. Materiais de construção civil e Princípios de ciências e Engenharia de materiais: concreto de cimento Portland. São Paulo: IBRACON, 2010. Cap. 29.

ORBIT INTELIGENCE. [Ferramenta de busca de bases de dados-Internet]. (CQuestel;2018. Disponível em: www.orbit.com. Acesso em: 2 dez. 2018.

PAIM Fabiane Gomes; ALMEIDA, Márcia Rego Sampaio de. Estudo prospectivo sobre a utilização da impressora 3d na área da construção civil. Cadernos de Prospecção, Salvador, v. 11, Edição Especial, p.463-474, 2018. Disponível em: https://rigs.ufba.br/index.php/nit/article/view/23379/ ESTUDO\%20PROSPECTIVO\%20SOBRE\%20A\%20UTILIZA\%C3\%87\%C3\%83O\%20DA\%20 IMPRESSORA\%203D\%20NA\%20\%C3\%81REA\%20DA\%20CONSTRU\%C3\%87\%C3\%83O\%20 CIVIL. Acesso em: 30 ago. 2019.

SILVA, Djalma Ribeiro. Estudo de inibidores de corrosão em concreto armado, visando a melhoria na sua durabilidade. 2006. 194 p. Tese (Doutorado) - Universidade Federal do Rio Grande do Norte, Natal, 2006. Disponível em: file://C:/Users/Viviane\%20Univasf/Downloads/ DjalmaRS.pdf. Acesso em: 15 fev. 2019.

TUTIKIAN, Bernardo F; HELENE, Paulo. Concreto e Tecnologia: dosagem dos concretos de cimento Portland. São Paulo: IBRACON, 2011. Cap. 12.

\section{Sobre os Autores}

\section{José Edilson dos Santos Júnior}

E-mail: jose.edilson@univasf.edu.br

Engenheiro Civil, Especialista em Saneamento e Gestão Ambiental.

Endereço profissional: Universidade Federal do Vale do São Francisco, campus Petrolina, Av. José de Sá Maniçoba, s/n, Centro, Petrolina, PE, Prefeitura Universitária. CEP: 56304-917.

\section{Vivianni Marques Leite dos Santos}

E-mail: vivianni.santos@gmail.com

Engenheira Química, Doutora em Química. 
Endereço profissional: Universidade Federal do Vale do São Francisco, campus Juazeiro, Av. Antonio Carlos Magalhães, n. 510, Santo Antônio, Juazeiro, BA, Colegiado do Mestrado Profissional em Propriedade Intelectual e Transferência de Tecnologia para a Inovação. CEP: 48902-300.

\section{Isnaldo José de Souza Coelho}

E-mail: isnaldo.coelho@univasf.edu.br Engenheiro Elétrico.

Endereço profissional: Universidade Federal do Vale do São Francisco, campus Juazeiro, Av. Antonio Carlos Magalhães, n. 510, Santo Antônio, Juazeiro, BA, Colegiado do Mestrado Profissional em Propriedade Intelectual e Transferência de Tecnologia para a Inovação. CEP: 48902-300. 